\title{
Advanced Instrumentation, Information and Control (II\&C) Research and Development Facility Buildout and Project Execution of LWRS II\&C Pilot Projects 1 and 3
}

Ronald Farris

Johanna Oxstrand Gregory Weatherby

September 2011

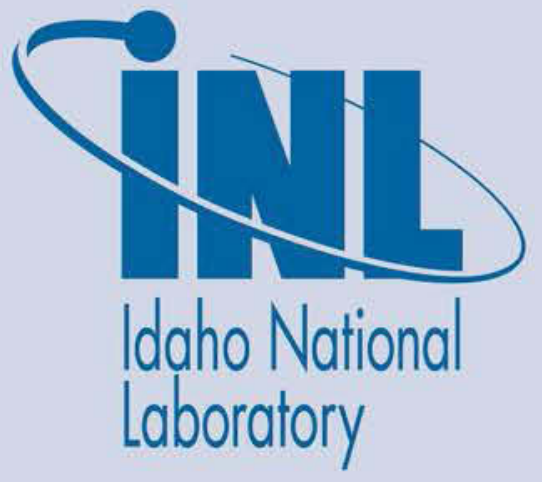

The INL is a U.S. Department of Energy National Laboratory operated by Battelle Energy Alliance 


\section{DISCLAIMER}

This information was prepared as an account of work sponsored by an agency of the U.S. Government. Neither the U.S. Government nor any agency thereof, nor any of their employees, makes any warranty, expressed or implied, or assumes any legal liability or responsibility for the accuracy, completeness, or usefulness, of any information, apparatus, product, or process disclosed, or represents that its use would not infringe privately owned rights. References herein to any specific commercial product, process, or service by trade name, trade mark, manufacturer, or otherwise, does not necessarily constitute or imply its endorsement, recommendation, or favoring by the U.S. Government or any agency thereof. The views and opinions of authors expressed herein do not necessarily state or reflect those of the U.S. Government or any agency thereof. 


\title{
Advanced Instrumentation, Information and Control (II\&C) Research and Development Facility Buildout and Project Execution of LWRS II\&C Pilot Projects 1 and 3
}

\author{
Ronald Farris, INL
}

Johanna Oxstrand, INL

Gregory Weatherby, INL

September 2011

Idaho National Laboratory

Idaho Falls, Idaho 83415

http://www.inl.gov

Prepared for the

U.S. Department of Energy

Office of Nuclear Energy

Under DOE Idaho Operations Office

Contract DE-AC07-05ID14517 



\section{CONTENTS}

ACRONYMS

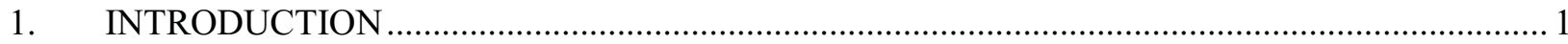

2. OUTAGE CONTROL CENTER AND WORK EXECUTION CENTER MODERNIZATION PILOT PROJECT CRADA NO. 11-CR-06 ............................................. 3

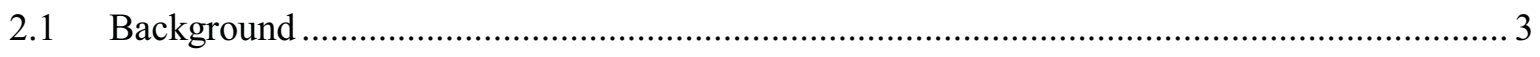

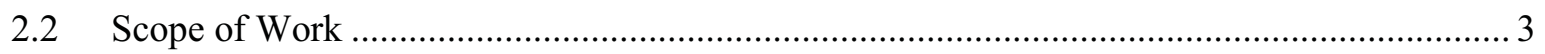

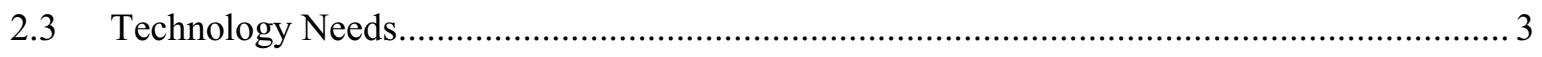

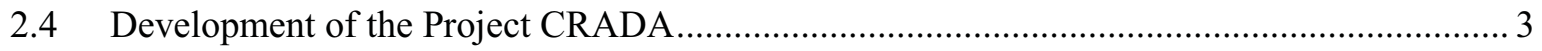

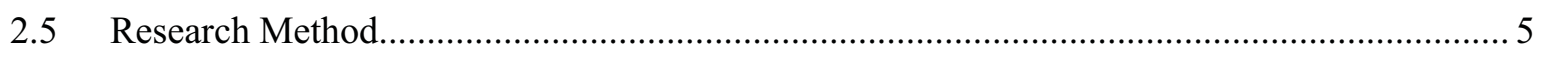

2.6 Technology Selection (Establishing a Foundation Technology) ........................................... 5

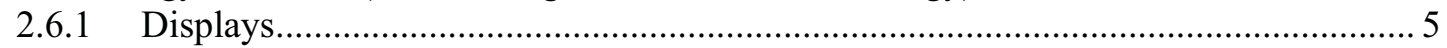

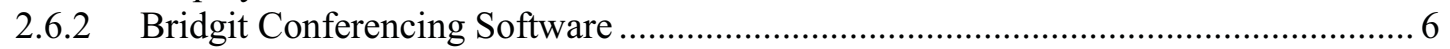

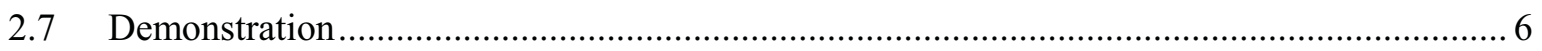

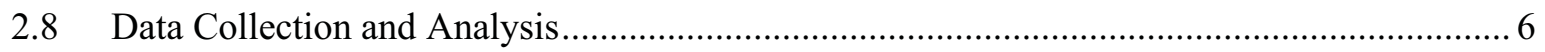

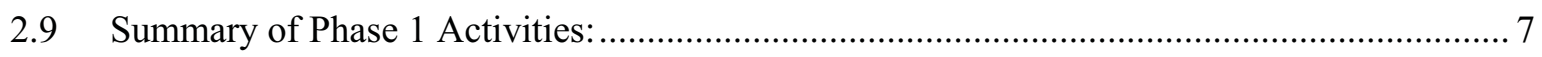

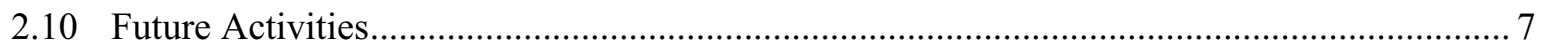

2.11 Engagement with Industry at Conferences and Seminars during 2011............................. 8

3. HUMAN PERFORMANCE PILOT PROJECT CRADA NO. 11-CR-08 ....................................... 9

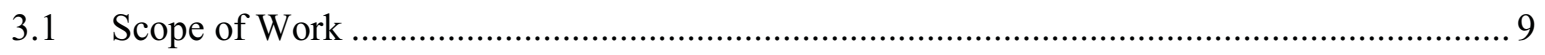

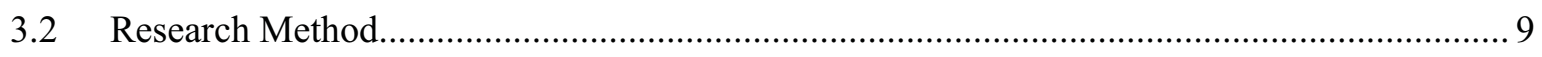

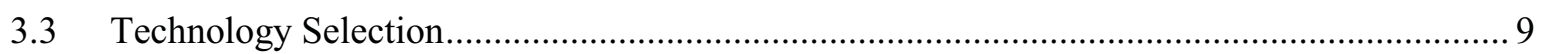

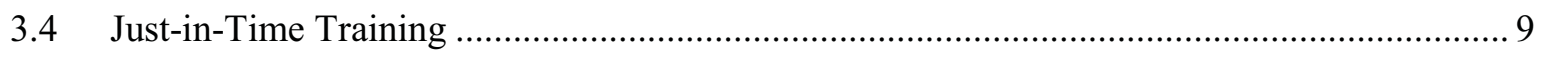

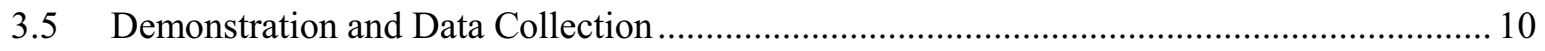

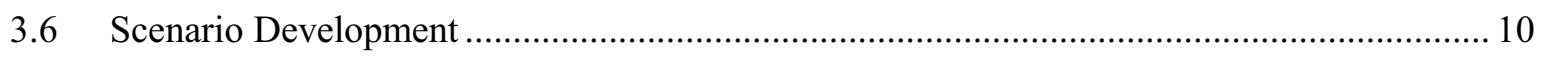

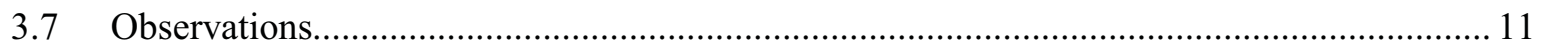

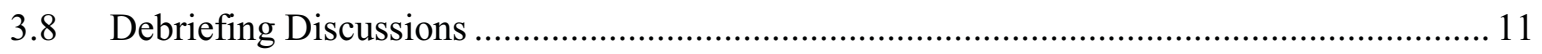

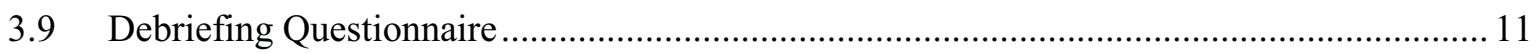

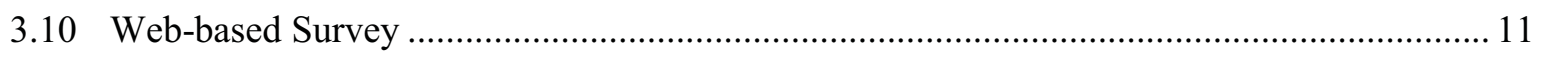

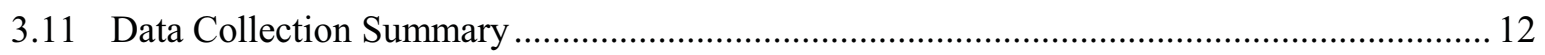

3.12 Engagement with Industry at Conferences and Seminars during 2011.............................. 12

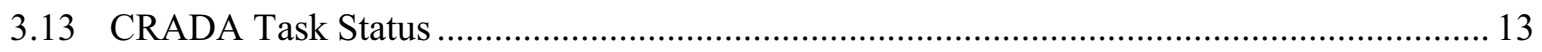

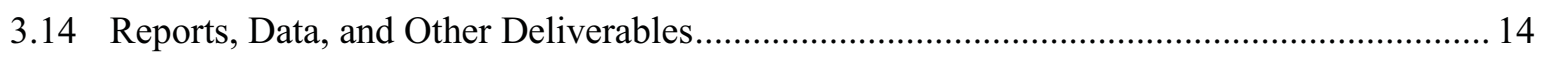

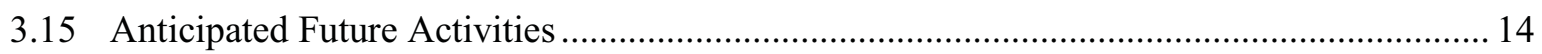

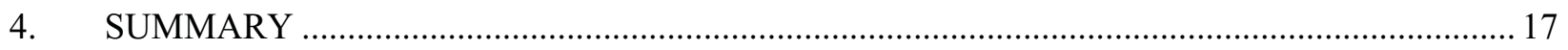

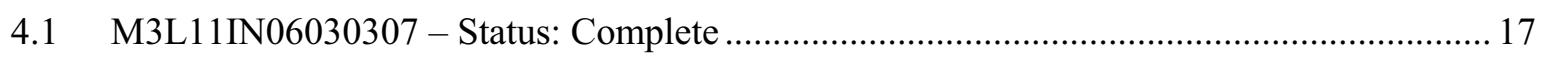

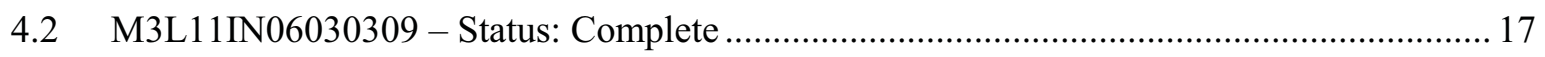




\section{FIGURES}

Figure 1. Simulation of remote proximity and radiation level monitoring capabilities............................. 8

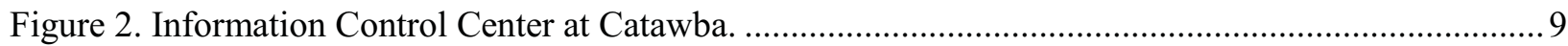

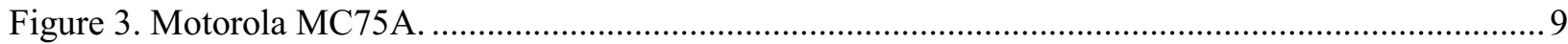

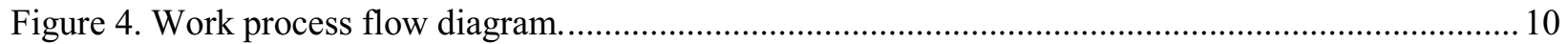

Figure 5. Nuclear Equipment Operator scanning equipment tag during Catawba scenario. ..................... 11

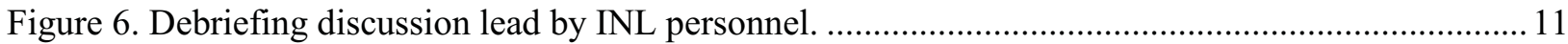

\section{TABLES}

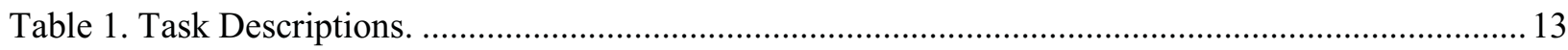

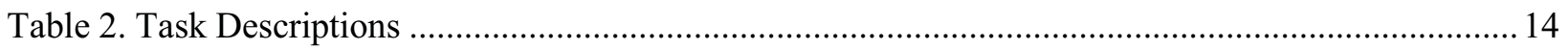




\section{ACRONYMS}

BEA Battelle Energy Alliance, LLC

CAES Center for Advanced Energy Studies

CRADA Cooperative Research and Development Agreement

CV Concurrent Verification

DOE Department of Energy

DViT Digital Vision Touch

DV Dual Verification

FME Foreign Material Exclusion

HD High Definition

HPRCT Human Performance Root-Cause and Trending

II\&C Instrumentation, Information, and Controls

INL Idaho National Laboratory

IT Information Technology

LCD Liquid Crystal Display

LWRS Light Water Reactor Sustainability

MCR Main Control Room

NEO Nuclear Equipment Operator

NPP Nuclear Power Plant

OCC Outage Control Center

R\&D Research and Development

RDD\&D Research Development, Demonstration, and Deployment

WCC Work Control Center

WEC Work Execution Center 


\section{Advanced Instrumentation, Information and Control (II\&C) Research and Development Facility Buildout and Project Execution of LWRS II\&C Pilot Projects 1 and 3}

1. INTRODUCTION

The U.S. Department of Energy (DOE) is sponsoring research, development, and deployment on light water reactor sustainability (LWRS), in which Idaho National Laboratory (INL) is working closely with nuclear utilities to develop technologies and solutions to help ensure the safe operational life extension of current reactors. As technologies are introduced that change the operation of the plant, the LWRS pilot projects can help identify their best-advanced uses and help demonstrate the safety of these technologies. In early testing of operator performance given these emerging technologies will ensure the safety and usability of systems prior to large-scale deployment and costly verification and validation at the plant. The aim of these collaborations, demonstrations, and approaches are intended to lessen the inertia that sustains the current status quo of today's Instrumentation, Information, and Controls (II\&C) systems technology, and to motivate transformational change and a shift in strategy to a long-term approach to II\&C modernization that is more sustainable. Advanced instrumentation and information pilot projects will conduct research that employs new instrumentation to monitor and assess the performance of nuclear power plant systems and techniques for using the resulting information (e.g., signals) to improve state awareness, availability, and performance in power generation.

Research being conducted under Pilot Project 1 regards understanding the conditions and behaviors that can be modified, through either process improvements and/or technology deployment, to improve the overall safety and efficiency of outage control at nuclear facilities. The key component of the research in this pilot project is accessing the delivery of information that will allow researchers to simulate the control room, outage control center (OCC) information, and plant status data. The simulation also allows researchers to identify areas of opportunity where plant operating status and outage activities can be analyzed to increase overall plant efficiency.

For Pilot Project 3 the desire is to demonstrate the ability of technology deployment and the subsequent impact on maximizing the "Collective Situational Awareness" of the various stakeholders in a commercial nuclear power plant. Specifically, the desire is to show positive results in plant status control, information management, knowledge management, and "Real-Time-Truth" as it relates to the current plant conditions.

The following report includes two attachments; each attachment represents Pilot Project 1 and 3. The two attachments also provide a report on two distinct milestones that were completed and are described below:

- M3L11IN06030307 - Complete initiation of two pilot projects

Complete initiation of pilot projects on real-time configuration management and control to overcome limitations with existing permanent instrumentation and real-time awareness of plant configurations; two candidate projects that consider low-cost wireless technology for in situ configuration monitoring and candidate technologies and an information architecture for outage management and control will be initiated with utilities. 
- M3L11IN06030309 - Complete data collection, research and development (R\&D) plans, and agreements needed to conduct the two pilot projects

Complete data collection conducted at pilot project utilities to support real-time configuration management and outage control center pilot studies conducted; R\&D plan for pilot projects produced and needed agreements established to support R\&D activities. 


\section{OUTAGE CONTROL CENTER AND WORK EXECUTION CENTER MODERNIZATION PILOT PROJECT CRADA NO. 11-CR-06}

\subsection{Background}

Nuclear plant outages represent one of the most significant areas where improvement can be realized in the important areas of safety and efficiency. Outages are when nuclear plants are the most vulnerable to conditions that can create expensive outage extensions and long-term problems. Common problems with outages include: systems or equipment deficiencies that are not identified during the outage, quality of the work performed, failures in inspection, inadequate vendor support, and deficient outage management. ${ }^{\text {a }}$ As a recent example (2011), a single piece of foreign material inadvertently left in a plant turbine caused an 11-day outage extension at a cost of \$15-20 million to the utility.

\subsection{Scope of Work}

This outage pilot project will support the commercial nuclear industry by improving both safety and efficiency during nuclear plant outages. Success in this area will enable nuclear utilities to cut costs during outages, shorten outage duration, reduce safety vulnerabilities, thus, becoming more cost competitive. These efforts directly support the U.S. Department of Energy's (DOE's) Light Water Reactor Sustainability (LWRS) Program goals to develop technologies and other solutions that can improve reliability, sustain safety, and extend the life of current reactors.

\subsection{Technology Needs}

As industry evolves, technology improves, and a new generation of managers and operators emerge, outage teams will expect nuclear plant technology to keep pace with the new technology available in the marketplace. Integrated information sharing and prioritization, as well as direct links with suppliers, engineers, vendor technical teams, and management decision makers will increase efficiency. Wireless proximity tracking, workplace three-dimensional modeling, remote dose information monitoring, and heads-up displays are some of the capabilities that commercial utilities desire and are willing to participate in through DOE Cooperative Research and Development Agreements (CRADAs).

\subsection{Development of the Project CRADA}

The work covered under the CRADA primarily consists of research and development of new methods of increasing safety and efficiency during scheduled nuclear plant outages. The Contractor (Battelle Energy Alliance, LLC [BEA]/Idaho National Laboratory [INL]) is providing expertise in the areas of human performance, nuclear operations evaluation, and new technology applications. The Participant (Exelon) is providing expertise in the areas of plant operations, outage control, and access to their facilities for outage evaluation and installation of government-owned test equipment, and access to operational information for building an operations and outage simulator at INL.

Exelon is a leading nuclear utility and with Exelon Nuclear, representing approximately $20 \%$ of the U.S. nuclear industry's power capacity with 10 power plants and 17 reactors that are located in Illinois, Pennsylvania, and New Jersey. INL is a science-based, applied engineering national laboratory dedicated to supporting the DOE's missions in nuclear and energy research, science, and national defense. The Nuclear Science and Technology organization uses a unique mix of human factors, nuclear operations, and instrumentation professionals to solve issues related to nuclear plant efficiency and safety. This expertise is not available in the commercial sector.

a. Nuclear Power Plant Outage Optimization Strategy, IAEA-TECDOC-1315. International Atomic Energy Agency, October 2002. 
The CRADA is limited to the research necessary to develop and pilot forward-looking technology (i.e. Hardware, software, displays, hand-held devices, radiological and proximity devices, etc.) that will enhance safe plant operations, improve human performance, reduce radiation exposure, and increase overall operational efficiency. One of the key components of the project is Contractor access to Participant facilities and the Participant's delivery of information that will allow Contractor to simulate the control room, outage control center (OCC) information, and plant status data.

The CRADA was developed and signed in February of 2011 with project work commencing immediately afterwards. Phase 1 of the CRADA is now complete and included the following:

- PHASE 1: Byron Outage Preparation And Initial Technology Deployment

- $\quad$ Task 1: Initial Training and Security Badging

Selected contractor employees will be trained at participant facilities, based on participant's rotating facility training schedule, for the purpose of unescorted access to participant facilities. This task will also include a security background check. Occasionally, the contractor may identify additional personnel that will be required to receive participant site access. The contractor and participant will work together to coordinate the training and security needs of the project. Training for facility access and security checks are generally accomplished within 1 week and are conducted at participant facilities.

- $\quad$ Task 2: Observation of Dresden Outage

Contractor personnel will be an observer during actual outage activities conducted at the participant's Dresden facility. This task will collect information on participant outage techniques and make recommendations on deployment of technology to increase efficiency during the March 2011 outage at the participant's Byron facility outage.

- $\quad$ Task 3: Byron Outage Technology Deployment

Contractor, working in conjunction with participant management and technical representatives, will recommend, purchase, and deliver selected technologies (hardware, software, displays, handheld devices, radiological and proximity devices, etc.) Participant will install the selected technologies and assure they are in working order prior to the commencement of the Byron plant actual outage scheduled for March 2011. In addition, the contractor will install technology at INL that will allow monitoring of OCC/Work Execution Center (WEC) activities during the outage and provide a live video link between INL and the Byron OCC for the purpose of daily project briefs and monitoring of actual outage activities.

- $\quad$ Task 4: Deployment of BEA Technical Professionals

In preparation of the Byron outage, the contractor will deploy a technical professional to the Byron facility prior to the scheduled outage for the purpose of identifying key processes and techniques used during Exelon outages. During the outage, contractor team members will be present in the OCC, WEC, and other locations at the facility to gather information on the outage process. Contractor will evaluate these processes and techniques and recommend improvements once the outage is completed. It is anticipated that contractor team members will have access to participant's outage personnel to obtain information needed to complete the investigative process. 


\begin{tabular}{|l|l|l|l|l|}
\hline \multicolumn{5}{|c|}{ Byron Outage Preparation and Initial Technology Deployment } \\
\hline $\begin{array}{l}\text { Task } \\
\text { No. }\end{array}$ & \multicolumn{1}{|c|}{ Tasks } & \multicolumn{1}{|c|}{ Contractor Role } & \multicolumn{1}{c|}{ Participant Role } & Months \\
\hline 1 & $\begin{array}{l}\text { Initial Training and } \\
\text { Security Badging }\end{array}$ & Joint Performance & Participant Lead & $1-3$ \\
\hline 2 & $\begin{array}{l}\text { Observation of Dresden } \\
\text { Outage }\end{array}$ & Joint Performance & Support & $3-4$ \\
\hline 3 & $\begin{array}{l}\text { Byron Outage } \\
\text { Technology Deployment }\end{array}$ & Joint Performance & Support & $3-5$ \\
\hline 4 & $\begin{array}{l}\text { Deployment of } \\
\text { Participant Technical } \\
\text { Professional }\end{array}$ & Contractor Lead & Joint Performance & $4-5$ \\
\hline
\end{tabular}

\subsection{Research Method}

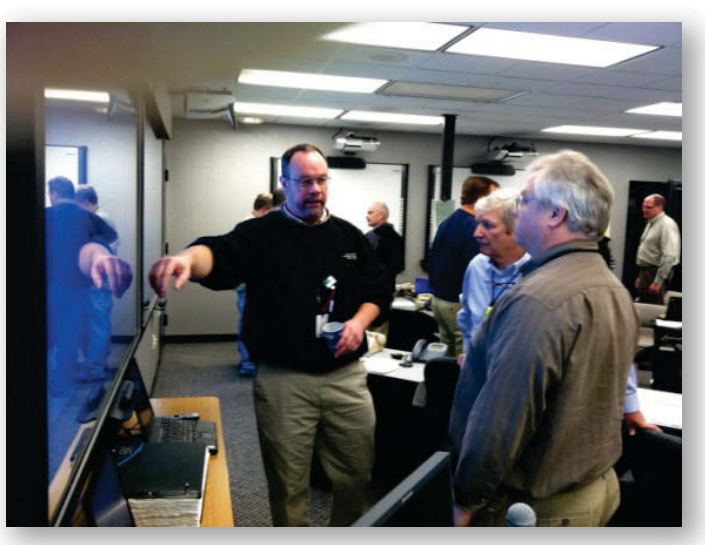

Phase 1 of the Outage Pilot Project was designed to increase communication both within the plant OCC and between the OCC and the WEC. The research team, along with Exelon, determined that best way to test this upgrade was to use a non-intrusive method of technology application. The technology would be available for the outage team to use, but did not restrict the outage management team from using previously deployed methods of communicating and recording outage activities. This naturalistic-type approach would allow the team to evaluate the effectiveness of the technology upgrade in real-time and to work closely with actual users to develop new and innovative uses to improve communication.

\subsection{Technology Selection (Establishing a Foundation Technology)}

Four SMART Technologies 6052 SMART Boards and five Hitachi Starboards were installed and configured to allow the outage control managers and personnel to communicate between remote locations in a collaborative manner. Bridgit conferencing software was used to allow communication between remotely located SMART Boards. The Hitachi boards were purchased by Exelon as a plant upgrade and were not considered integral to the INL research team. However, they were available to the outage team as an alternative to the SMART Board technology.

\subsubsection{Displays}

SMART Boards were selected to replace existing dry-erase whiteboards currently in use by the outage team. The SMART Board ${ }^{\circledR} 6052 \mathrm{i}$ interactive display is a touch-enabled liquid crystal display (LCD) designed to provide access to digital materials and make interacting with information a more intuitive and engaging experience. The $6052 \mathrm{i}$ combines a professional-grade LCD with SMART's DViT (Digital Vision Touch) technology to provide a large, high-quality display that

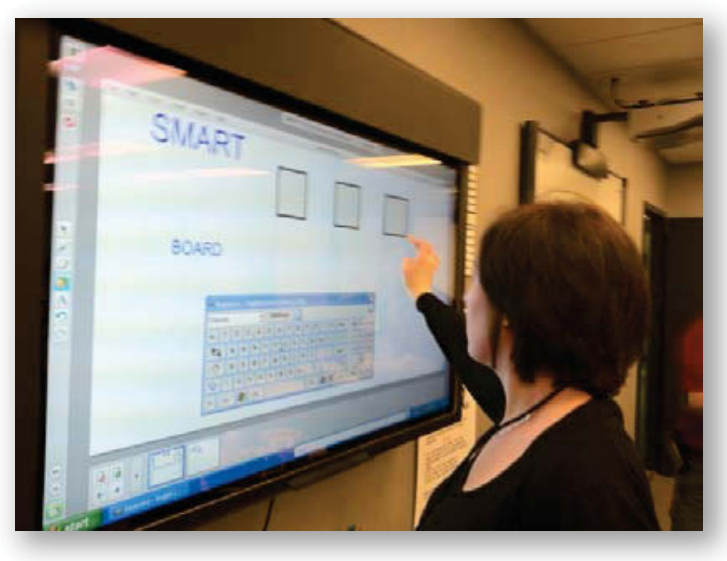


can easily operate using a finger or the pencil tool. This widescreen, projector-free system also supports high definition (HD) and eliminates shadows, improving both the visibility and impact of critical information.

The SMART Boards were selected as a foundation technology that will allow the team to expand the capabilities of the display system as future technologies are selected in follow-on phases of the pilot project to improve communication, safety, and efficiency.

\subsubsection{Bridgit Conferencing Software}

SMART Bridgit software makes distance collaboration interactive. Any session participant can share their SMART Board interactive whiteboard or desktop with the group, so everyone can see the same applications, documents, critical path information, or plant conditions. Information can be highlighted by writing over a shared desktop, or any user can take control of another participant's desktop to demonstrate a concept or provide assistance. More than one person can write over a desktop at the same time, so ideas can be exchanged quickly and easily.

\subsection{Demonstration}

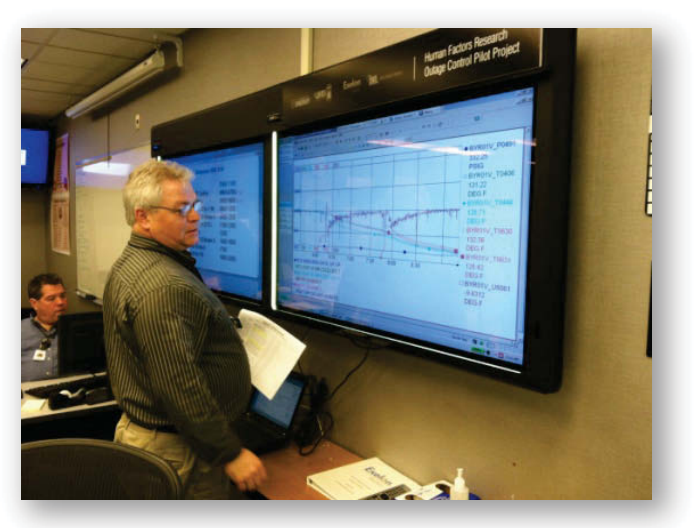

As the scheduled date for the Exelon Byron outage approached (March 2011), the SMARTboard and Hitachi displays were installed and outage managers were trained in their use. A representative from the SMART Technology vendor provided the training and was on hand to mentor the use of the SMART Boards and provide technical support during their initial set up and use.

\subsection{Data Collection and Analysis}

Following the SMART Board training, outage managers were asked to interact with the technology to become familiar with its use. Up to this, point it was unknown how seasoned outage managers would interact with the change to their normal operating methods (use of telephones and radios to communicate with remote locations, and moving away from the use of dry-erase whiteboards). Data was collected through direct observation and interviews during the outage.

The objective of the data collection effort was to investigate if the staff perceived a change in their communication and collaboration due to the new technology. The two SMART Boards in the OCC were dedicated to display critical path items, major milestones, and emergent issues. These boards were also utilized during the reoccurring status meetings. One SMART Board was installed in the WEC. It was decided by the operations staff to have this board display the same screen as the critical path board in the OCC. This enabled the WEC to receive real-time updates of schedule changes and updates to the critical path. As soon as the outage manager changed the information on the board in the OCC, the change would appear simultaneous on the board in the WEC.

The main conclusions of the data collection and analysis were:

- The real-time sharing of information between the OCC and the WEC was very beneficial. Managers directly involved in this task estimated that this technology could save them at least 2 hours per day due to the reduced time spent walking back and forth between the two locations.

- Another conclusion from the data analysis is regarding record keeping. All updates and changes made to the critical path are saved as electronic records. Unlike when using a whiteboard, the day shift can go back and see what changes the night shift made etc. With whiteboards, this information is erased (destroyed) every time one needs to make room for new information. 
- The ability to have an electronic record was viewed as helpful for both the current outage and for the planning of future outages. The electronic record would be used to extract the amount of time it actually took to perform an item on the critical path, as well as which items that suffered from delays.

- It was also noted that the more organizations were starting to see the value of accessing the information in the OCC and want to find out how to gain this access.

\subsection{Summary of Phase 1 Activities:}

The deployment of the foundation technologies at the Byron plant confirmed that:

- Outage managers were accepting of the new technologies and their capabilities

- The SMART connectivity capabilities will be a useful foundation for the addition of new system additions (enhanced audio/video displays, decision-making collaborations, increased connectivity with other plant and management locations, etc.) in future outages

- Outage managers were beginning to develop unique and useful applications for the technologies as they interacted with them

- The technologies were not overly complex for use by managers who had no previous experience with the tools.

\subsection{Future Activities}

The BEA/INL research team will continue to gather information for continued improvements to the outage process in 2011/2012 by:

- Near Term:

- Actively participating in technology use during the Exelon Byron outage scheduled for September/October of 2011.

- Participating in Outages with Southern Nuclear, Palo Verde Nuclear Generating Station, and other selected utilities.

- A Utility Outage improvement advisory group, facilitated by the BEA/INL research team, is being formed to advise the research team on needed applications to improve safety and efficiency during outages. Participation commitments have been received from Southern Nuclear, Exelon, Arizona Public Service, PG\&E, and others.

- The research team will continue to benchmark new technologies and efficiency upgrades by forming strong ties to utilities and the technology industries during 2012 and beyond.

- Opportunities for participation in hands-on technology demonstrations and research will be expanded to other nuclear utilities during 2012.

- The BEA/INL research team will further enhance its working relationship with the Halden Reactor Project (Norway) to gather outage improvement technologies and process improvements from European and Asian nuclear plants. A member of the Halden Reactor Project is currently a contributing member of the BEA/INL research team. 


\section{- Extended Term:}

- $\quad$ Large-scale Touch Screen Technology Fast

- 3-D modeling, feeds, and real-time proximity/locating of personnel (see Figure 1)

- Emerging issue management (mobile/reconfigurable work stations, real-time feeds),

- Shift-change statusing/pre-job briefings

- OCC/field interface enhancements

- Remote Hand Held Tools for Electronic Procedure Use

- Wearable eyewear with heads-up procedures and safety/hazards identification capabilities

- $\quad$ Exact job status reporting (\% complete v. predicted or reported)

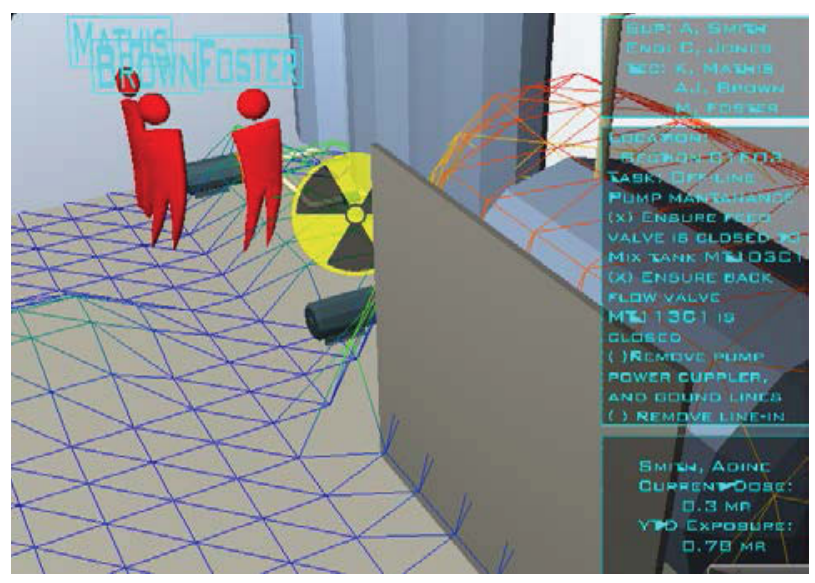

Figure 1. Simulation of remote proximity and radiation level monitoring capabilities.

- Staging of QA/safety personnel at procedure hold points

- Predictable time estimation for job completion (“on-deck" teams)

- Visual reference for workers/management (Remote Team Problem Solving)

- Bar-code scanning for tools, calibration, training

- Real-time Dosimetry (personnel dose/dose remaining)

- $\quad$ Foreign Material Exclusion Tracking (Visual Verification)

- Integrated Warehouse/Supply Chain functions

- Lessons learned/training for task development, critiques, and task modification

- Development of the OCC for emergency actions, remote maintenance management, and emerging issues collaboration.

\subsection{Engagement with Industry at Conferences and Seminars during 2011}

The BEA/INL/Exelon research team actively participated in knowledge transfer by presenting in the following activities in 2011.

- Outage Pilot Project Vision and Objectives during the annual American Nuclear Society meeting in Las Vegas, Spring 2011

- Phase 1 research findings to Exelon corporate information technology (IT) management (May 2011)

- Phase 1 research findings at the Human Performance Root-Cause and Trending (HPRCT) annual conference (June 2011)

- Phase 1 research findings at the Utility Working Group Managers meeting (August 2011) Presented by Exelon management

- Phase 1 findings and objectives to LWRS Utility Working Group (September 2011). 


\section{HUMAN PERFORMANCE PILOT PROJECT CRADA NO. 11-CR-08}

\subsection{Scope of Work}

The objective of this pilot project was limited to the applied research necessary to develop and pilot forward looking technology that will enhance safe plant operations, improve human performance, increase overall operational efficiency, and improve plant status control.

Research activities were primarily performed at Duke Energy's Catawba Nuclear Power Plant (NPP). In addition, a research/simulator laboratory work took place at Idaho National Laboratory's (INL) Center for Advanced Energy Studies (CAES) facility in Idaho Falls, Idaho.

One element of the original CRADA is no longer being pursued by this research effort - wireless position indication devices. This element will be addressed in a companion project.

\subsection{Research Method}

As a part of the science based approach, an applied research model has been used to structure this research effort. The focus of which is to solve practical problems. Compared to basic research, applied research is commonly based on empirical methodologies and does not always have access to large data samples. Thus, it is important that there is transparency in the methodology used so that the study can be reproduced even though the data and result might differ slightly.

\subsection{Technology Selection}

It was decided early on that use of off-the-shelf technology to the extent possible as an addition to utilizing existing research paradigms. The purpose of the research effort is to show proof of concepts rather that development of a field deployable product. It is also of importance to show the nuclear industry that the concepts developed and demonstrated within this research effort is within their reach instead of something very futuristic, which they cannot use now.

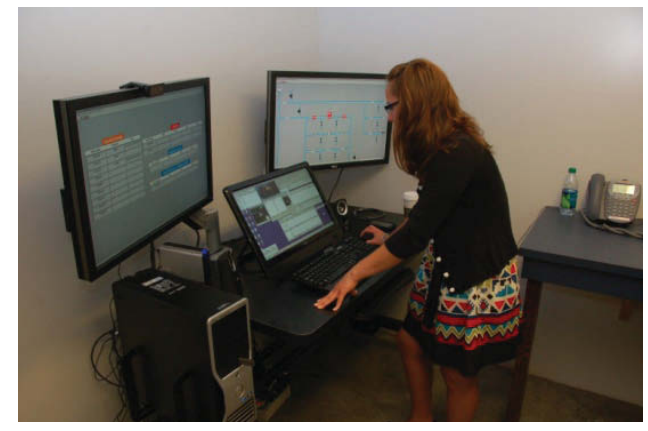

Figure 2. Information Control Center at Catawba.

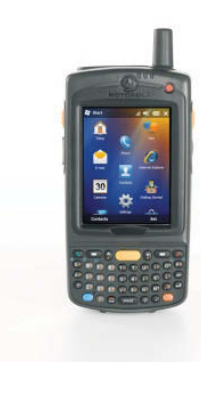

Figure 3. Motorola MC75A.

\subsection{Just-in-Time Training}

Just-in-Time training was developed to support participants in use of the handheld device (Motorola MC75A). The training was given in a written form and then INL staff provided a demonstration to the first Catawba personnel to run through the scenario. The initial participants (two nuclear equipment operators [NEOs]) provided additional training to subsequent participants. Each participant was asked to train the next group of participants. An observation by INL staff was the ease that the subsequent training occurred along with knowledge transfer on the embedded error prevention tools provided by the software. 


\subsection{Demonstration and Data Collection}

To understand the current work process at the utility and to indentify which areas that could be improved by utilizing technical solution, a process mapping exercise was conducted early on in the project. Both INL and Catawba team members participated in the exercise. The process focused on identification of a station critical problem through work execution. The process maps were used as the basis for scenario development and concept demonstration at the nuclear station.

\subsection{Scenario Development}

The purpose of the scenario was to create a foundation for the research development, demonstration, and deployment (RDD\&D) process. The technology utilized, ready to use software, and the software that was developed by INL in the first phase was designed to ensure that it could be used to proof the concepts explored in the initial phase of the project. During the demonstration at the station, the participants worked though the scenario either as independent or paired operators. During this exercise, the research team collected both qualitative and quantitative data. One example of process mapping is shown in Figure 4.

\section{Work Assignment}

- Non-Critical Problem

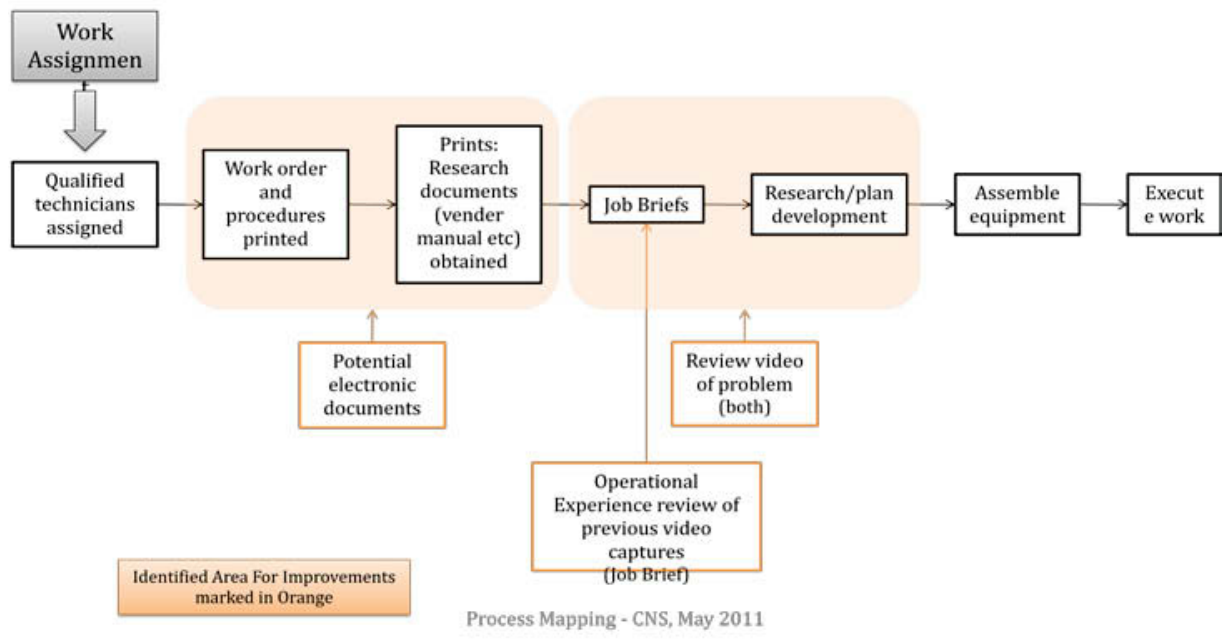

Figure 4. Work process flow diagram. 


\subsection{Observations}

Observations of all runs though the scenario was conducted by the research team during the demonstration at the utility. Notes were taken on the fly by INL researchers that captured comments made by the participants while working through the scenario (see Figure 5), as well as observed interactions and potential usability issues with the technology and software. As an observation aid, most runs though the scenario were videotaped and along with pictures. Other persons that had run though the scenario or were waiting for their turn, also observed the scenario. The comments and impressions from these observations were captured in formal debriefing discussions.

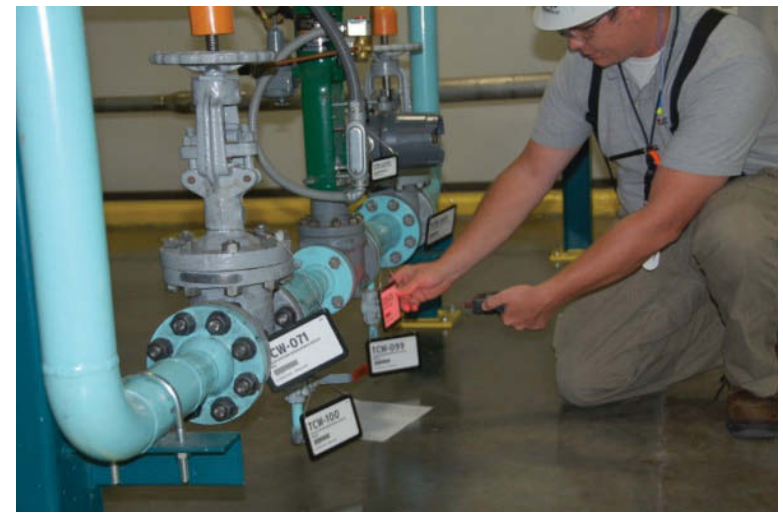

Figure 5. Nuclear Equipment Operator scanning equipment tag during Catawba scenario.

\subsection{Debriefing Discussions}

After each run through of the scenarios, all participants - both the people that had worked through the scenario and the ones observing - had a debriefing discussion (see Figure 6). The discussion was lead by the research team. The discussions were captured in thorough notes as well as on video.

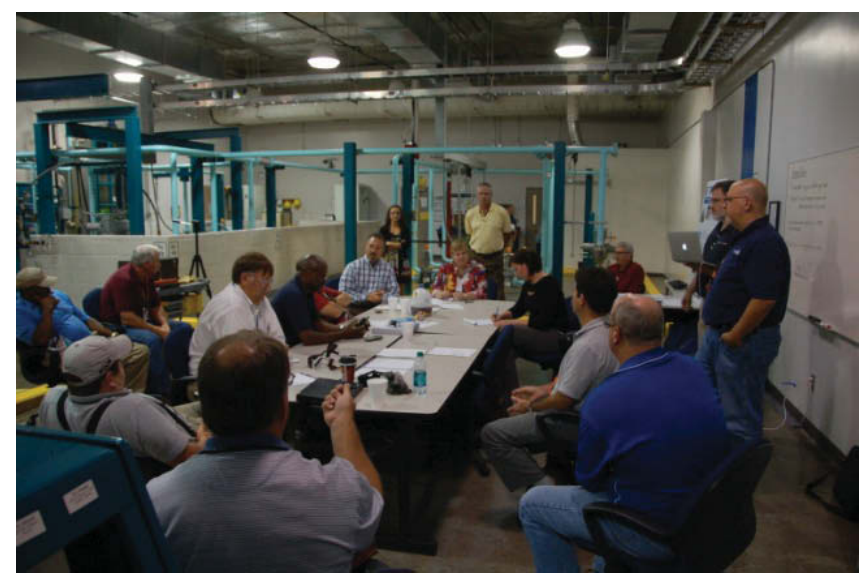

Figure 6. Debriefing discussion lead by INL personnel.

\subsection{Debriefing Questionnaire}

A paper-based questionnaire was developed for post-demonstration at Catawba. The questionnaire was designed to capture both qualitative and quantitative data provided by the demonstration participants. The questions captured data regarding current work processes used for common and current work processes in comparison to the technology-enhanced process utilized in the scenario.

\subsection{Web-based Survey}

As an addition to the debriefing questionnaire a web-based survey was developed. Everyone that participated in the demonstration at the utility was invited to take part of the web survey as well. The invitation to the survey was distributed a week after the demonstration. The purpose of the web survey was to capture additional feedback and comments the participants. As well, as capture more qualitative 
and quantitative data that will guide the next phase of the research effort. The improvements to the current software application and interfaces will be based on the results from the web survey, field observations, debriefing discussions, and the debriefing questionnaire.

\subsection{Data Collection Summary}

The data collected in the different efforts described above were thoroughly analyzed. Based on the data it can be concluded that the project is on the correct path and that the research effort is much appreciated by the utility and well accepted by the workforce. The data indicates that the main and most important benefit to introducing new technology at the utility will be an increased focus on tasks rather than processes (i.e., error reduction tools). This will help reduce human error rate as well as result in large time savings throughout the organization. Presented below is a summary the data analysis:

- In the current process there are many steps between the problem identification and until the problem is solved. Any steps that can be reduced are opportunities to reduce human errors.

- The technology should be viewed as a situation awareness tool rather than a human performance tool. The technology allows the staff to conduct more from their work location, which reduces time and errors due to knowledge transfer issues.

- The technology enables everyone to see the same thing at the same time (i.e. "collective situational awareness"), which will help reduce the rates of human errors.

- The different technologies have to be more streamlined and seamlessly integrated.

- New system should match the current work processes.

- It would be very useful to have access to additional information while being out in the plant- both accessible when scanning a component or tag barcode accessible on a server or from the device directly.

- The ability to do remote verification from the information center at the same time as the activity is conducted in the plant will save a lot of time for the utility.

- Having easy access to documents, procedures, manuals, etc., without having to go back to the office will significantly reduce the "stop work" time.

- The technology will help the operations organization save a lot of time in the work request process. The operator will be able to continue the round directly after submitting the work request.

\subsection{Engagement with Industry at Conferences and Seminars during 2011}

The BEA/INL/Duke research team actively participated in the following engagement activities in 2010/2011:

- Presented Plant Status Control overview during working group session at the annual American Nuclear Society meeting in Las Vegas, Spring 2010

- Presented Phase 1 research findings from the research working for plant status control to Exelon corporate IT management (May 2011)

- Presented Phase 1 research findings at the Human Performance Root-Cause and Trending (HPRCT) annual conference (June 2011)

- Industry representatives (Duke, Southern, Exelon and EPRI) attended and participated in research activity at Catawba (August 2011)

- Presented Phase 1 findings and objectives to LWRS Utility Working Group (September 2011). 


\subsection{CRADA Task Status}

Table 1 summarizes the status of the task and subtasks identified in the CRADA.

Table 1. Task Descriptions.

\begin{tabular}{|c|c|c|c|c|}
\hline Task No. & Tasks & INL Role & $\begin{array}{c}\text { Duke Energy } \\
\text { Role }\end{array}$ & Status \\
\hline 1 & Task 1: Planning and Evaluation & & & \\
\hline 1.1 & Define details of demonstration & Lead & Support & Complete \\
\hline 1.2 & Evaluate plant issues & Support & Lead & Complete \\
\hline 1.3 & Benchmarking & Lead & Support & Complete \\
\hline 1.4 & Plant Component Status & Lead & Support & Complete \\
\hline 2 & Task 2: Technology Deployment & & & \\
\hline 2.1 & Technology selection & Lead & Support & Complete \\
\hline 2.2 & Technology deployment & Support & Lead & Complete \\
\hline 3 & Task 3: Training and Evaluation & & & \\
\hline 3.1 & Initial usage & Support & Lead & Complete \\
\hline 3.2 & Training & Support & Lead & Complete \\
\hline 3.3 & $\begin{array}{l}\text { Evaluation/Decision on Full } \\
\text { Deployment }\end{array}$ & $\begin{array}{l}\text { Joint } \\
\text { Performance }\end{array}$ & $\begin{array}{l}\text { Joint } \\
\text { Performance }\end{array}$ & $\begin{array}{l}\text { FY } 2012 \\
\text { Effort }\end{array}$ \\
\hline 4 & $\begin{array}{l}\text { Task 4: Scaled-up Technology } \\
\text { Deployment }\end{array}$ & & & \\
\hline 4.1 & Deployment/scale-up & Support & Lead & $\begin{array}{l}\text { FY } 2012 \\
\text { Effort }\end{array}$ \\
\hline 4.2 & Measure improvements & Lead & Support & $\begin{array}{l}\text { FY } 2012 \\
\text { Effort }\end{array}$ \\
\hline 4.3 & Document/present results & Lead & Support & $\begin{array}{l}\text { FY } 2012 \\
\text { Effort }\end{array}$ \\
\hline
\end{tabular}




\subsection{Reports, Data, and Other Deliverables}

Table 2 summarizes the deliverables identified in the CRADA.

Table 2. Task Descriptions

\begin{tabular}{|c|c|c|c|}
\hline $\begin{array}{l}\text { Task No. } \\
\text { Reference }\end{array}$ & Deliverable & $\begin{array}{l}\text { Responsible } \\
\text { Party }\end{array}$ & Status \\
\hline 1.2 & $\begin{array}{l}\text { Duke Energy event reports delivered to INL for } \\
\text { evaluation }\end{array}$ & Duke Energy & Complete \\
\hline 1.3 & Benchmarking results & INL & Complete \\
\hline 2.1 & $\begin{array}{l}\text { Select technology devices to support research in the } \\
\text { Catawba NPP }\end{array}$ & INL & Complete \\
\hline 3.1 & $\begin{array}{l}\text { Develop a training plan and provide training to NPP } \\
\text { operators on selected technology }\end{array}$ & INL & Complete \\
\hline 4.3 & $\begin{array}{l}\text { Final Report - Research paper based on research } \\
\text { activities }\end{array}$ & INL & $\begin{array}{l}\text { FY } 2012 \\
\text { Effort }\end{array}$ \\
\hline 3.3 & Report of initial usage results, with collected data & Duke Energy & Complete \\
\hline 3.3 & Research paper based on collected data & INL & $\begin{array}{l}\text { FY } 2012 \\
\text { Effort }\end{array}$ \\
\hline 4.2 & $\begin{array}{l}\text { Report of measured improvements based on Project } \\
\text { Success Measures for Scaled-Up Deployment }\end{array}$ & Duke Energy & $\begin{array}{l}\text { FY } 2012 \\
\text { Effort }\end{array}$ \\
\hline
\end{tabular}

\subsection{Anticipated Future Activities}

The INL/Duke research team will continue to gather information from industry partners for continued improvements for plant status control issues in 2012 by:

\section{- Near Term:}

- Leading two complex research activities at the Catawba Flow Loop scheduled for November of 2011:

- Normal operations in the Flow Loop (initial system lineup and startup, emergent issue recognition and disposition)

- Normal maintenance activity (diesel generator maintenance and emergent issue recognition and disposition) in the Catawba maintenance training facility.

- Continue to assemble an array of mobile technologies that constitute a platform for field activities in a NPP to address correct component (correct train/plant) identification through the following:

- Bar Code Reader

- Procedural linkage between action and component verification

- Visual concurrent verification by remote operator at Information Control Center.

- The research team will continue to benchmark new technologies and efficiency upgrades by forming strong ties to utilities and the technology industries during 2012 and beyond.

- Hands-on technology demonstrations and research will continue to be focused on real plant issues 2012.

- A Plant Status Control improvement interest group, facilitated by the INL research team, is being formed to discuss and advice the research team on needed applications to improve the use of wireless technologies in improving plant status control, information management, knowledge 
management, improved productivity, efficiency, and safety. Participants will include but not be limited to Duke Energy, Southern Nuclear, Exelon, Arizona Public Service, and Progress.

- The BEA/INL research team will further enhance its working relationship with the Halden Reactor Project (Norway) to gather outage improvement technologies and process improvements from European and Asian nuclear plants. A member of the Halden Reactor Project is currently a contributing member of the BEA/INL research team.

\section{- Extended Term:}

- Develop and test use of wireless technologies to promote and enhance information sharing during emergency operations

- Remote maintenance management

- $\quad$ Emerging issues decision making (parallel vs. series decision making)

- Develop electronic procedure for work request, work orders, online maintenance activities, work clearance orders (danger and caution tagging), emergency and normal operations

- $\quad$ Mixed Reality - provide field workers with a blend of real, virtual, augmented reality, and virtual reality

- Provide improved pre-job briefings through technology (video feeds from Operational Experience data base)

- Exact job status reporting (\% complete versus predicted or reported)

- Data display for field deployed worker:

- Diagrams (and other reference material such as data lists, specs, etc.)

- Work Orders

- Procedures (Need to include place keeping, checklists, and Dual Verification and Concurrent Verification (DV/CV) requirements. Also need the ability to record data - such as test or measurement readings. Is there a means to do these types of things?)

- Technical manuals

- Operating Experience (related items of interest)

- Training Material

- Dose Survey Maps

- Clearances

- Personal Safety Information (e.g., stay times, confined space)

- Plant risk information, protected train/equipment, etc.

- Engineering Instructions

- Security Compensation Measures (e.g., for breached security barriers).

- Visual Communication

- Still Camera

- Video Camera

- Skype function (within firewall)

- Remote feed (e.g. from a borescope or camera on a pole to look into a high-rad area)

- Messaging capability from Work Control Center (WCC) or Main Control Room (MCR).

- Audio Communications

- (Including ability to set up a job specific bridge line for the individuals involved in a particular job (field, WCC, MCR, and/or Maintenance Shop) 
- Real-time environmental field data (ambient temperature, humidity, contamination levels, dose rate,

- Ambient Conditions (temperature, humidity, noise, etc.)

- Physiological - personal parameters (heart rate, breathing rate, heat stress, skin temperature, dehydration, fatigue, anxiety, rehabilitation, etc.)

- Personnel Location - indoor/outdoor physical location, posture (laying or standing, stationary, and walking)

- Radiological data - dose rate, cumulative dose, radiation field, hot spots, Low Dose Waiting Areas (LDWA), contamination areas and airborne radiation areas 


\section{SUMMARY}

\subsection{M3L11IN06030307 - Status: Complete}

Pilot Projects 1 and 3 initiated pilot projects on real-time configuration management and control to overcome limitations with existing permanent instrumentation and real-time awareness of plant configurations; the two projects utilized low-cost wireless technology for in situ configuration monitoring and candidate technologies and information architecture for outage management and control at the participating utility facilities.

\subsection{M3L11IN06030309 - Status: Complete}

Pilot Projects 1 and 3 collected data at the participating utilities to support real-time configuration management and outage control center pilot studies and produced R\&D plans for pilot projects and needed agreements were established to support R\&D activities. 